\title{
Exposure to organic solvents and personality
}

\author{
R Chen, F Dick, S Semple, A Seaton, L G Walker
}

\begin{abstract}
Objectives-Although cognitive and neuropsychological changes have been found after high cumulative exposures to solvents, it is not clear whether such exposures are associated with personality characteristics. To study this two groups of British and Chinese dockyard painters who had been heavily exposed to paint solvents have been investigated.
\end{abstract}

Methods-260 Male dockyard painters in the United Kingdom, 539 local community controls, 109 Chinese dockyard painters, and 255 dockyard controls completed the Eysenck personality questionnaire, neuroticism (N) and social conformity or dissimulation (L) scales. The nonparametric Kruskal-Wallis test was used to evaluate differences in scores of personality traits between painters and controls. Adjusted relative risks for painters having high $\mathbf{N}$ and $\mathbf{L}$ scores were calculated in $\mathbf{a}$ Breslow-Cox regression analysis, and exposure-response relations were examined in multivariate logistic regression analysis. Non-parametric Spearman's correlation was used to examine relations between previously determined neuropsychological symptoms and personality. Results-Both British and Chinese data showed that mean neuroticism scores of painters were significantly higher than controls, whereas scores of social conformity did not differ. Relative risk of being a painter increased significantly with increasing $\mathbf{N}$ scores, but $L$ scores showed no such trend. In a case-control analysis, there were significant exposureresponse relations for the $\mathrm{N}$ score. In the United Kingdom the odds ratios (ORs) (95\% confidence interval $(95 \% \mathrm{CI})$, were $2.03(0.79$ to 5.22$)$ for $1-4$ years of exposure, 2.38 (0.82 to 6.91) for 5-9 years, 7.05 (1.27 to 39.25$)$ for $10-14$ years, and $1.76(0.63$ to 4.89$)$ for $15-41$ years. In the Chinese painters, ORs were 4.66 (1.38 to

Table 1 Scores of neuroticism and social conformity among painters and their controls

\begin{tabular}{|c|c|c|c|c|c|c|c|c|}
\hline \multirow[b]{3}{*}{ Personality } & \multicolumn{2}{|c|}{ United Kingdom } & \multicolumn{6}{|l|}{ China } \\
\hline & \multicolumn{2}{|l|}{ Men } & \multicolumn{2}{|l|}{ Total } & \multicolumn{2}{|l|}{ Men } & \multicolumn{2}{|l|}{ Women } \\
\hline & $\begin{array}{l}\text { Painters } \\
n=260\end{array}$ & $\begin{array}{l}\text { Controls } \\
n=539\end{array}$ & $\begin{array}{l}\text { Painters } \\
n=109\end{array}$ & $\begin{array}{l}\text { Controls } \\
n=255\end{array}$ & $\begin{array}{l}\text { Painters } \\
n=60\end{array}$ & $\begin{array}{l}\text { Controls } \\
n=184\end{array}$ & $\begin{array}{l}\text { Painters } \\
n=49\end{array}$ & $\begin{array}{l}\text { Controls } \\
n=71\end{array}$ \\
\hline \multicolumn{9}{|c|}{ Neuroticism: } \\
\hline Median & 4 & 3 & 4 & 1 & 3 & 1 & 4 & 1 \\
\hline Mean & 4.67 & 4.00 & 3.97 & 1.64 & 3.90 & 1.60 & 4.06 & 1.73 \\
\hline SD & 3.34 & 3.25 & 2.89 & 2.28 & 3.00 & 2.34 & 2.78 & 2.14 \\
\hline $\mathrm{p}$ Value & 0.006 & & $<0.001$ & & $<0.001$ & & $<0.001$ & \\
\hline \multicolumn{9}{|c|}{ Social conformity: } \\
\hline Median & 7 & 6 & 9 & 9 & 9 & 9 & 9 & 10 \\
\hline Mean & 6.51 & 6.11 & 8.96 & 9.18 & 9.05 & 9.05 & 8.86 & 9.52 \\
\hline SD & 2.84 & 2.85 & 1.39 & 1.57 & 1.57 & 1.62 & 1.15 & 1.40 \\
\hline $\mathrm{p}$ Value & 0.062 & & 0.072 & & 0.979 & & 0.002 & \\
\hline
\end{tabular}

15.75) for $2-14$ years, 10.03 (2.96 to 34.04 ) for 15-18 years, and 13.56 (3.78 to 48.59 ) for 19-43 years. Neuroticism was significantly positively related to neuropsychological symptoms in all subjects. Social conformity showed no association with neuropsychological symptoms in British painters and a negative relation among the Chinese painters.

Conclusion-Increasing symptoms suggesting neuroticism seemed to relate to the duration of painting whereas scores for social conformity and dissimulation did not. The relation between exposure time and response suggests that increased neuroticism may be caused by long term occupational exposure to organic solvents.

(Occup Environ Med 2001;58:14-18)

Keywords: organic solvents; painter; dockyards; personality; neuroticism; social conformity

Concerns about possible health hazards of organic solvents in the workplace have been raised and many studies have examined cognitive changes and neuropsychological symptoms. ${ }^{1}$ Some studies have suggested that exposure to solvents may produce a range of adverse changes in mental state, such as anxiety, depression, irritability, and fatigue. ${ }^{2-5}$ Any possible effects of exposure to solvents on personality characteristics - that is, stable, transsituational traits-as opposed to mental state, have been relatively little investigated in population studies, although anecdotal clinical evidence suggests that exposure to solvents may cause personality changes.

We have previously reported two cross sectional studies of dockyard painters and community controls, in Britain and in China, in which we showed increased neuropsychological symptoms among the painters. ${ }^{67}$ As part of this study we examined the relations between neuroticism, a factorially derived second order dimension of personality, and

Medicine, University of Aberdeen Medical School, Foresterhill, Aberdeen AB25 2ZD, Scotland, UK

$\mathrm{R}$ Chen

F Dick

S Semple

A Seaton

Institute of

Rehabilitation,

University of Hull, UK

L G Walker

Correspondence to:

Professor Anthony Seaton

a.seaton@abdn.ac.uk

Accepted 12 September 2000 
Table 2 Relative risks of neuroticism and social conformity in British painters $v$ controls

\begin{tabular}{|c|c|c|c|c|c|c|c|c|}
\hline \multirow[b]{2}{*}{ Personality } & \multirow[b]{2}{*}{ Score ${ }^{\star}$} & \multicolumn{3}{|c|}{ Subjects (n) } & \multirow[b]{2}{*}{$R R$} & \multirow[b]{2}{*}{$95 \% C I$} & \multirow[b]{2}{*}{$R R t$} & \multirow[b]{2}{*}{$95 \% \mathrm{CI}+$} \\
\hline & & Controls & Painters & Total & & & & \\
\hline \multicolumn{9}{|l|}{ Neuroticism: } \\
\hline Lowest sixth & 0 & 78 & 27 & 105 & 0.72 & 0.48 to 1.08 & 0.62 & 0.40 to 0.98 \\
\hline 2nd & 1 & 71 & 30 & 101 & 0.88 & 0.59 to 1.31 & 0.96 & 0.61 to 1.50 \\
\hline $3 \mathrm{rd}$ & $2-3$ & 132 & 52 & 184 & 0.82 & 0.61 to 1.09 & 0.94 & 0.67 to 1.32 \\
\hline 4th & $4-5$ & 93 & 51 & 144 & 1.14 & 0.84 to 1.55 & 1.20 & 0.84 to 1.71 \\
\hline 5 th & $6-7$ & 72 & 39 & 111 & 1.12 & 0.78 to 1.61 & 0.99 & 0.66 to 1.49 \\
\hline Highest sixth & $8-12$ & 93 & 61 & 154 & 1.36 & 1.02 to 1.81 & 1.28 & 0.91 to 1.80 \\
\hline \multicolumn{9}{|c|}{ Social conformity: } \\
\hline Lowest sixth & $0-2$ & 76 & 25 & 101 & 0.68 & 0.45 to 1.05 & 0.73 & 0.46 to 1.17 \\
\hline 2nd & $3-4$ & 79 & 46 & 125 & 1.21 & 0.87 to 1.68 & 1.17 & 0.80 to 1.72 \\
\hline $3 \mathrm{rd}$ & $5-6$ & 134 & 48 & 182 & 0.74 & 0.55 to 1.00 & 0.71 & 0.50 to 0.99 \\
\hline 4 th & 7 & 68 & 40 & 108 & 1.22 & 0.85 to 1.75 & 1.28 & 0.84 to 1.93 \\
\hline 5 th & $8-9$ & 116 & 59 & 175 & 1.05 & 0.80 to 1.39 & 1.04 & 0.75 to 1.45 \\
\hline Highest sixth & $10-12$ & 66 & 42 & 108 & 1.32 & 0.92 to 1.89 & 1.38 & 0.92 to 2.08 \\
\hline
\end{tabular}

* Original score.

†Adjusted for age, alcohol drinking, education level, smoking, and social conformity (for neuroticism analysis only).

Table 3 Relative risk of neuroticism and social conformity in Chinese painters $v$ controls

\begin{tabular}{|c|c|c|c|c|c|c|c|c|}
\hline \multirow[b]{2}{*}{ Personality } & \multirow[b]{2}{*}{ Score ${ }^{*}$} & \multicolumn{3}{|c|}{ Subjects (n) } & \multirow[b]{2}{*}{$R R$} & \multirow[b]{2}{*}{$95 \% C I$} & \multirow[b]{2}{*}{$R R t$} & \multirow[b]{2}{*}{$95 \% \mathrm{CI} \dagger$} \\
\hline & & Controls & Painters & Total & & & & \\
\hline \multicolumn{9}{|l|}{ Neuroticism: } \\
\hline Lowest third & 0 & 113 & 12 & 125 & 0.25 & 0.14 to 0.43 & 0.27 & 0.15 to 0.50 \\
\hline Middle third & $1-2$ & 82 & 30 & 112 & 0.86 & 0.60 to 1.22 & 0.95 & 0.61 to 1.48 \\
\hline Highest third & $3-11$ & 60 & 67 & 127 & 2.61 & 2.00 to 3.41 & 2.25 & 1.53 to 3.32 \\
\hline \multicolumn{9}{|c|}{ Social conformity: } \\
\hline Lowest third & $2-8$ & 70 & 32 & 102 & 1.07 & 0.75 to 1.52 & 1.14 & 0.73 to 1.79 \\
\hline Middle third & 9 & 68 & 43 & 111 & 1.48 & 1.09 to 2.02 & 1.24 & 0.82 to 1.87 \\
\hline Highest third & $10-12$ & 117 & 34 & 151 & 0.68 & 0.50 to 0.93 & 0.74 & 0.50 to 1.12 \\
\hline
\end{tabular}

^Original score.

†Adjusted for age, sex, alcohol drinking, education level, smoking, and social conformity (for neuroticism analysis only).

various indices of exposure to solvents. A measure of dissimulation-that is, deliberate misrepresentation-was used to check the validity of the personality data. In this paper we report the results of our analyses of the relations between exposure to solvents and the personality traits neuroticism and social conformity and dissimulation.

Table 4 Case-control multivariate analysis of personality: British subjects with high scores $v$ those with low score

\begin{tabular}{|c|c|c|c|c|}
\hline \multirow[b]{2}{*}{ Variable } & \multicolumn{2}{|c|}{ Neuroticism } & \multicolumn{2}{|c|}{ Social conformity } \\
\hline & $O R$ & $95 \% C I$ & OR & $95 \% C I$ \\
\hline \multicolumn{5}{|l|}{ Years of painting exposure at the dockyard } \\
\hline $1-4$ & 2.03 & 0.79 to 5.22 & 2.51 & 0.74 to 8.47 \\
\hline $5-4$ & 2.38 & 0.82 to 6.91 & 1.57 & 0.40 to 6.14 \\
\hline $10-14$ & 7.05 & 1.27 to 39.25 & 3.67 & 0.88 to 15.23 \\
\hline $15-41$ & 1.76 & 0.63 to 4.89 & 3.38 & 0.63 to 18.26 \\
\hline Age $(v 19-34$ years old $)$ & 1.00 & & 1.00 & \\
\hline $35-44$ & 1.69 & 0.60 to 4.71 & 2.72 & 0.74 to 10.05 \\
\hline $45-54$ & 2.57 & 0.94 to 7.03 & 8.10 & 2.28 to 28.87 \\
\hline $55-64$ & 1.22 & 0.44 to 3.37 & 20.03 & 5.13 to 78.11 \\
\hline $65-96$ & 0.99 & 0.31 to 0.314 & 65.00 & 13.83 to 305.4 \\
\hline Education ( $v$ no training) & 1.00 & & 1.00 & \\
\hline Apprenticeship & 0.60 & 0.28 to 1.30 & 1.22 & 0.46 to 3.23 \\
\hline Technical college & 0.76 & 0.34 to 1.70 & 0.50 & 0.20 to 1.25 \\
\hline University and above & 0.83 & 0.22 to 3.05 & 0.28 & 0.06 to 1.44 \\
\hline Smoking ( $v$ never smoker): & 1.00 & & 1.00 & \\
\hline Ex-smoker & 1.03 & 0.50 to 2.14 & 0.46 & 0.18 to 1.13 \\
\hline Current-smoker & 0.83 & 0.40 to 1.72 & 0.75 & 0.29 to 1.93 \\
\hline Alcohol intake ( $v 0$ unit/week) & 1.00 & & 1.00 & \\
\hline $1-4$ & 0.47 & 0.18 to 1.23 & 0.67 & 0.23 to 1.98 \\
\hline $5-9$ & 0.79 & 0.26 to 2.41 & 0.32 & 0.08 to 1.25 \\
\hline $10-14$ & 0.62 & 0.22 to 1.76 & 1.08 & 0.33 to 3.53 \\
\hline $15-22$ & 1.27 & 0.45 to 3.54 & 0.57 & 0.15 to 2.15 \\
\hline$\geqslant 23$ & 1.35 & 0.49 to 3.69 & 0.73 & 0.21 to 2.51 \\
\hline Scores of social conformity ( $v 0-2$ scores) & 1.00 & & NA & \\
\hline $3-4$ & 0.52 & 0.17 to 1.54 & NA & \\
\hline $5-6$ & 0.75 & 0.28 to 2.03 & NA & \\
\hline 7 & 0.56 & 0.17 to 1.85 & NA & \\
\hline $8-9$ & 0.21 & 0.08 to 0.58 & NA & \\
\hline $10-12$ & 0.12 & 0.04 to 0.38 & NA & \\
\hline
\end{tabular}

$\mathrm{NA}=$ social conformity score was adjusted for neuroticism analysis only.

\section{Subjects and methods}

Selection of the subjects has been described previously, in two papers in which we described their mortality and neuropsychological symptoms. ${ }^{67}$ In brief, the subjects exposed to solvent in the United Kingdom were derived from a cohort of 1292 male painters who had worked in the paint shop at a Scottish dockyard for at least 1 year between 1950 and 1992. Nine hundred and fifty three surviving painters from the cohort and 953 controls (non-painters randomly selected from the local population) were invited to participate in a questionnaire study in 1996. Of those able to be contacted, 260 painters and 539 controls completed their questionnaires, a practical response rate of $48.5 \%$ for painters and $62.0 \%$ for controls. ${ }^{6}$ Meanwhile in China, 116 dockyard painters (66 men and 50 women) and 263 workers not exposed to solvents (75 women, $188 \mathrm{men}$ ), who had worked for at least 1 year in Anhui dockyards, were identified in 1997. Of the painters $94 \%$, and of the controls $97 \%$ completed the questionnaires. ${ }^{7}$ Selection bias was avoided by recruiting subjects for a study of the health of people who had worked or did work in the relevant area, and by not mentioning a specific interest in paints or solvents.

The questionnaire included personal details on occupation, smoking, alcohol consumption, and neuropsychological symptoms. ${ }^{6}$ Also, it included the 12 statements of the neuroticism (N) scale and the 12 statements of the dissimulation and social conformity (L) scale of the Eysenck personality questionnaire short scale (EPI) ${ }^{8}$ Each of the $\mathrm{N}$ and L statements is answered by yes or no, and scores on each scale 
Table 5 Case-control multivariate analysis of personality: Chinese subjects with high scores $v$ those with low score

\begin{tabular}{|c|c|c|c|c|}
\hline \multirow[b]{2}{*}{ Variable } & \multicolumn{2}{|c|}{ Neuroticism } & \multicolumn{2}{|c|}{ Social conformity } \\
\hline & OR & $95 \% C I$ & OR & $95 \% C I$ \\
\hline $\begin{array}{l}\text { Years of painting exposure at the dockyard } \\
\text { ( } v \text { non-exposure) }\end{array}$ & 1.00 & & 1.00 & \\
\hline $2-14$ & 4.66 & 1.38 to 15.75 & 0.65 & 0.21 to 2.03 \\
\hline $15-18$ & 10.03 & 2.96 to 34.04 & 0.34 & 0.12 to 0.99 \\
\hline $19-43$ & 13.56 & 3.78 to 48.59 & 0.93 & 0.39 to 2.20 \\
\hline Sex (women $v$ men) & 1.45 & 0.67 to 3.15 & 1.02 & 0.51 to 2.03 \\
\hline Age ( $v$ 18-29 years old) & 1.00 & & 1.00 & \\
\hline $30-39$ & 1.29 & 0.38 to 4.43 & 1.74 & 0.57 to 5.30 \\
\hline $40-49$ & 0.89 & 0.30 to 2.69 & 3.12 & 1.14 to 8.55 \\
\hline $50-59$ & 0.92 & 0.29 to 2.88 & 1.42 & 0.52 to 3.91 \\
\hline $60-82$ & 0.62 & 0.20 to 1.93 & 1.74 & 0.64 to 4.76 \\
\hline Education ( $v$ no training) & 1.00 & & 1.00 & \\
\hline Apprenticeship & 1.03 & 0.48 to 2.22 & 0.85 & 0.42 to 1.75 \\
\hline Technical college & 0.97 & 0.38 to 2.47 & 0.89 & 0.37 to 2.10 \\
\hline Smoking ( $v 0$ cigarettes/day) & 1.00 & & 1.00 & \\
\hline $1-19$ & 0.62 & 0.26 to 1.48 & 0.85 & 0.40 to 1.81 \\
\hline$\geqslant 20$ & 1.36 & 0.52 to 3.55 & 0.70 & 0.30 to 1.62 \\
\hline Alcohol intake ( $v 0$ unit/week $\left.{ }^{\star}\right)$ & 1.00 & & 1.00 & \\
\hline $0.5-2.9$ & 1.21 & 0.44 to 3.30 & 1.05 & 0.45 to 2.46 \\
\hline$\geqslant 3.0$ & 2.49 & 1.09 to 5.71 & 0.98 & 0.46 to 2.06 \\
\hline Scores of social conformity ( $v 2-8$ scores) & 1.00 & & NA & \\
\hline 9 & 0.40 & 0.18 to 0.87 & NA & \\
\hline $10-12$ & 0.50 & 0.25 to 1.01 & NA & \\
\hline
\end{tabular}

${ }^{\star}$ Chinese wine unit-Liang.

$\mathrm{NA}=$ social conformity score was adjusted for neuroticism only.

range from $0-12$. In the Chinese investigation, the questionnaire was translated into Chinese. ${ }^{7}$

We analysed British and Chinese data separately with standard statistical packages of SPSS and SAS. The non-parametric KruskalWallis test was used to evaluate differences in scores of personality traits between painters and controls. Relative risks (RR) for painters who had high scores in $\mathrm{N}$ and $\mathrm{L}$ (sextiles for United Kingdom data; tertiles for Chinese data) were calculated in a Breslow-Cox regression model, ${ }^{9}$ with adjustments for age, educational level, smoking, and alcohol intake. A logistic regression model was used to estimate the magnitude of effects in a multivariate case-control analysis for the higher scores versus lower scores in $\mathrm{N}$ and $\mathrm{L}$.

We also used the non-parametric Spearman's correlation to examine relations between symptom scores and personality. The symptom scores were derived from the subjects' responses to the neuropsychological questionnaire, as reported previously. ${ }^{6}$ Eight questions contributed to the neurological score and 16 to the psychological score.

\section{Results}

Both British and Chinese data showed the distribution of $\mathrm{N}$ scores to be positively skewed, whereas that of $\mathrm{L}$ scores was close to normal.
The scores for neuroticism in the painters were significantly higher than in the controls in both countries, whereas the only significant difference in the scores of social conformity was that Chinese women obtained lower scores than their controls (table 1).

Relative risk for being a painter increased significantly in the United Kingdom data with increasing $\mathrm{N}$ scores ( $\mathrm{p}$ for trend 0.006), but not with increasing $\mathrm{L}$ scores ( $\mathrm{p}=0.060$, table 2 ). Chinese painters also showed a significant increase in relative risks with increasing $\mathrm{N}$ scores $(\mathrm{p}<0.001)$ but not with L scores (table 3). After adjustment for age, alcohol, educational level, smoking, and L score, these increased RRs for painters relative to high $\mathrm{N}$ score remained, although that of the highest score in the United Kingdom data did not reach conventional levels of significance.

In the case-control analysis, the logistic regression model showed the odds ratio (OR) for a British painter being an $\mathrm{N}$ case (scores $8-12 v 0)$ to be 1.89 (95\% confidence interval (95\% CI) 1.10 to 3.26), but that for L scores (10-12 v0-2) was 1.93 (1.07 to 3.51). In the Chinese data the corresponding values were 10.51 (5.28 to 20.94) for $\mathrm{N}$ scores (3-11 $v 0$ ) and 0.64 (0.36 to 1.12$)$ for L (10-12 v 2-8). In the unadjusted United Kingdom and Chinese data there seemed to be relations between exposure time and response for the $\mathrm{N}$ scores but not for L; in multivariate analysis, including age, educational level, smoking, alcohol, and L score, these relations were clear (tables 4 and 5). In these multivariate analyses, the highest L scores were also positively associated with age, whereas the $\mathrm{N}$ scores were positively associated with heavy alcohol consumption and negatively associated with the highest $\mathrm{L}$ scores; other factors were not significant.

Spearman's correlation showed a significantly positive relation between neuropsychological symptoms and neuroticism in both painters and controls (table 6). There was no significant relation between the symptoms and social conformity in United Kingdom data, whereas a negative relation was found in the Chinese data.

\section{Discussion}

Our original study investigated the associations between what we now know to have been very heavy industrial exposure to paints (and their associated solvents) and neuropsychological symptoms. ${ }^{6}$ We found strong evidence that such exposure was associated with increasing

Table 6 Correlations between neuropsychological symptoms and personality

\begin{tabular}{|c|c|c|c|c|c|c|c|c|}
\hline \multirow[b]{2}{*}{ Symptom score } & \multicolumn{2}{|c|}{ United Kingdom } & \multicolumn{6}{|l|}{ China } \\
\hline & $\begin{array}{l}\text { Men } \\
\text { Painters }\end{array}$ & Controls & $\begin{array}{l}\text { Total } \\
\text { Painters }\end{array}$ & Controls & $\begin{array}{l}\text { Men } \\
\text { Painters }\end{array}$ & Controls & $\begin{array}{l}\text { Women } \\
\text { Painters }\end{array}$ & Controls \\
\hline \multicolumn{9}{|l|}{ Neuroticism: } \\
\hline Psychological & 0.64 & 0.58 & 0.58 & 0.31 & 0.54 & 0.30 & 0.60 & 0.37 \\
\hline Neurological & 0.50 & 0.47 & 0.56 & 0.32 & 0.52 & 0.33 & 0.53 & 0.29 \\
\hline Total scores & 0.64 & 0.60 & 0.59 & 0.33 & 0.56 & 0.32 & 0.68 & 0.38 \\
\hline \multicolumn{9}{|l|}{ Social conformity: } \\
\hline Psychological & -0.10 & -0.10 & -0.45 & -0.22 & -0.56 & -0.24 & -0.32 & -0.18 \\
\hline Neurological & -0.10 & -0.01 & -0.50 & -0.23 & -0.55 & -0.24 & -0.43 & -0.19 \\
\hline Total scores & -0.12 & -0.08 & -0.48 & -0.24 & -0.58 & -0.25 & -0.38 & -0.20 \\
\hline
\end{tabular}

$\mathrm{p}<0.05$ for all figures not in italics; correlation coefficients. 
symptoms, and have now investigated this with formal neuropsychological testing. Some indication of these exposures can be found in two separate reports of the clinical features of some of the United Kingdom subjects studied subsequently. ${ }^{1011}$ In one paper we have reported the association of impairment of colour vision with estimates of exposure to mixed solvents averaging about the equivalent of $11 \mathrm{cal}-$ endar years working at the occupational exposure limit. ${ }^{10}$ On the other, we have reported clinical neurological disease in a group of workers exposed to the equivalent of between 13 and 37 calendar years of exposure to the occupational exposure limit (OEL). ${ }^{11}$ The associations originally found in the United Kingdom painters were tested and duplicated in a comparable group of Chinese workers. The $96 \%$ response rate was used to show that there was unlikely to have been any important selection bias in the larger United Kingdom study. ${ }^{7}$ We now report evidence of an interesting possible effect of solvents on personality.

The personality questionnaire we used has two scales, $\mathrm{N}$ and $\mathrm{L}$. The $\mathrm{N}$ scale measures the extent to which people are prone to worrying. According to Eysenck and Eysenck, ${ }^{8}$

“. . .we may describe the typical high $\mathrm{N}$ scores as being an anxious, worrying individual, moody and frequently depressed. He is overly emotional, reacting too strongly to all sorts of stimuli".

The L scale was initially developed to detect dissimulation and it has been shown to be a reliable and valid measure of this. ${ }^{12}$ However, Eysenck and Eysenck have also stated that

“ . . .the L scale also measures some stable personality factor which may possibly denote some degree of social naïvety or conformity". 8

Kirton has also argued that some people who score highly on this scale are not dissimulating but are, rather, genuinely naïve and honest. ${ }^{13}$ In the present study, the L scale was included both as a measure of dissimulation and of conformity.

Our results showed higher emotional reactivity ( $\mathrm{N}$ scores) both in United Kingdom and Chinese painters compared with their controls. Moreover, increasing $\mathrm{N}$ scores related to the duration of painting, even when possible confounding factors were allowed for in multiple regression analysis. In the Chinese data, the differences were greater than in the United Kingdom data, and this may reflect the different controls or higher exposures. The United Kingdom controls were derived from a random population sample whereas the Chinese controls were fellow workers, and therefore would have been expected to be relatively healthy compared with the general population. Nevertheless both British and Chinese data showed a significant association between exposure to paint solvents and neuroticism. This contrasted with the findings about social conformity, where no differences were found except among Chinese women. L Scores were generally higher among the Chinese, probably reflecting different background personality characteristics. No significant trends with duration of exposure were found in L scores.
Scores on the $\mathrm{N}$ scale have been shown to be affected by the circumstances in which the test is administered..$^{12}$ One possibility, therefore, is that the painters may have been dissimulating, resulting in distorted self reporting of their emotional symptoms. Two strengths of the present study, however, are the use of a validity scale and the inclusion of subjects of two different races. If either of the groups-for example, the painters - had been systematically dissimulating their results, there should have been a difference in the mean $\mathrm{L}$ scores in the two groups. This was not the case and there was no relation between $\mathrm{L}$ scores and the extent of exposure to solvents. These findings suggest that the difference in $\mathrm{N}$ scores between the groups is valid and not due to dissimulation. The finding of a relation between duration of exposure and increasing $\mathrm{N}$ scores also suggests that the findings are not due to dissimulation.

Several studies have suggested that exposure to solvents may lead to changes in mental state such as mood disturbance. ${ }^{2-5}$ Although $\mathrm{N}$ scores have been shown to reflect a stable personality trait, there is some evidence that clinically notable anxiety and depression can lead to transient changes in $\mathrm{N}$ scores. ${ }^{14}$ It is appropriate, therefore, to review the evidence for exposure to solvents causing symptoms of mood disturbance.

As early as the 1940s and 1950s, Lewey ${ }^{15}$ and Grandjean et $a l^{16}$ found that emotional symptoms were common among workers exposed to solvents. Such personality changes could result from the direct effect of solvents on the nervous system. However, they may occur indirectly and be secondary reactions to a declining level of psychological performance, ill health, or social changes due to intoxication or the effects of other factors in the work environment or private life. Subjects with evidence of severe intoxication, who show the psycho-organic syndrome, have shown changes in personality reactions in the form of apathy, loss of initiative, and lack of persistence. A high correlation has been found between neurotic manifestations and duration of exposure. Early studies by Gregersen $e t a l^{23}$ found that workers exposed to a range of solvents were inclined to be irritable and tearful, when a clinical rather than psychometric assessment was used. In a small study, Linz et $a l^{4}$ found tension or strain and nervousness to be equally common in painters and controls. Personality change was commoner in the painters, but the significance of this is impossible to evaluate. In an uncontrolled study, ${ }^{5} 22$ people who had been referred to an occupational medicine clinic and who had been exposed to a range of organic solvents were assessed with a personality inventory; as a group, they scored highly on anxiety and depression.

Lindstrom and Martelin ${ }^{17}$ investigated the relation between personality and organic exposure to solvents, and found that the duration of exposure of a group exposed to styrene related weakly to personality variables. A moderate but significant correlation has also been shown between neuropsychological measures and 
everyday functioning, including emotional and social adaptability. ${ }^{18}$ Morrow et $a l^{5}$ indicated that those people who had been working the longest with neurotoxins were most likely to report disturbances of thinking, peculiarities of perception, poor concentration, social alienation, and apprehension.

The impact of personality disorders associated with dementia has often been emphasised, ${ }^{19}$ and although intellectual deficits, especially impaired memory, present a problem, these changes in personality also cause considerable trouble in daily life. ${ }^{20}$ They may contribute most to a person's social and psychological dependence and to family stress. ${ }^{21}$ ArlienSöborg $^{22}$ has pointed out that personality changes and psychosocial problems probably arise as a mixture of primary changes directly associated with the dementia, and of secondary reactive patterns. Feelings of insufficiency, almost universal in dementia, are clearly of a secondary nature. Specific studies of patients with the chronic effects of exposure to organic solvents have given descriptions similar to these. Symptoms of abnormal fatigue and personality changes have been pronounced in several studies. ${ }^{2}$ In most cases, however, personality changes are an integral part of the dementia syndrome and should therefore not be treated as something isolated and special. By contrast with their significance to the patient's life, personality changes have not played a major part in the medical diagnostic process.

Personality is usually quite stable for one person over a prolonged period, even in patients with serious diseases such as cancer. In our study, neuroticism had higher scores among painters and exposure-response relations were also found. It is said that social conformity, examining telling the truth, depends on education and living environments, whereas neuroticism, examining complaints, is partly subject to characteristics of the nervous system. Such interrelations of personality change and exposure to solvents in paint could therefore be considered to be secondary to the neuropsychological effects of the solvents. In other words, paint solvents may have led to damage to the nervous system, which in turn may have affected the neuroticism - that is, it may be a covariable. As well as giving reassurance that the differences in $\mathrm{N}$ are not due to dissimulation, the lack of significant differences in $\mathrm{L}$ scores between painters and controls also suggests that exposure to solvents does not affect social conformity. The significant negative relation between $\mathrm{L}$ scores and neuropsychological symptoms in the Chinese data suggests that the questions on social conformity may be unsuitable for Chinese subjects, because of different cultural backgrounds, etc.
We have already reported, in common with other studies, that these painters showed a markedly increased risk of neuropsychological problems, and that they had very high peak and cumulative exposures to solvents in their work, ${ }^{6}{ }^{10}{ }^{11}$ It seems likely to us that their personality abnormalities and neurological symptoms are interconnected and probably a consequence of these exposures.

This research formed part of the $\mathrm{PhD}$ thesis of $\mathrm{RC}$ for Aberdeen University. He was supported by a fellowship from the Colt Foundation and by a research grant from The Royal Society of London. Our current studies are supported by the British Occupational Health Research Foundation and the United Kingdom Health and Safety Executive.

1 Baker EL. A review of recent research on health effects of human occupational exposure to organic solvents. $\mathcal{F}$ Occup Med 1994;36:1079-92.

2 Gregersen P, Klausen H, Elsnab UC. Chronic toxic encephalopathy in solvent-exposed painters in Denmark year follow up. Am F Ind Med 1987;11:399-417.

3 Gregersen P, Angelso B, Nielsen TE, et al. Neurotoxic effects of organic solvents in exposed workers: an occupational, neuropsychological and neurological investigation. Am f Ind Med 1984;5:201-25.

4 Linz DH, de Garmo PL, Morton WE, et al. Organic solvent induced encephalopathy in industrial painters. $\mathcal{F}$ Occup Med 1986;28:119-25.

5 Morrow LA, Ryan CM, Goldstein G, et al. A distinct pattern of personality disturbance following exposure to mixtures of organic solvents. F Occup Med 1989;31:743-6.

6 Chen R, Dick F, Seaton A. Health effects of solvent exposure among dockyard painters: mortality and neuropsychological symptoms. Occup Environ Med 1999;56:3837.

7 Chen R, Wei L, Seaton A. Neuropsychological symptoms in Chinese male and female painters: an epidemiological study in dockyard workers. Occup Environ Med 1999;56: study in

8 Eysenck HJ, Eysenck SBJ. Manual of the Eysenck personality scales (EPS adult). London: Hodder and Stoughton, 1991. 9 Lee J. Odds ratio or relative risk for cross-sectional data? Int f Epidemiol 1994;23:201-3.

10 Semple S, Dick F, Osborne A, et al. Impairment of colour vision in workers exposed to organic solvents. Occup Environ Med 2000;57:582-7.

11 Dick F, Semple S, Chen R, et al. Neurological deficits in solvent-exposed painters: a syndrome including impaired colour vision, cognitive defects, tremor and loss of vibration sensation. QF Med 2000;93:653-9.

12 Michaelis W, Eysenck HJ. The determination of personality inventory factor patterns and intercorrelations by changes inventory factor patterns and intercorrelations by changes
in real life motivation. $\mathcal{F}$ Genet Psychol 1971;118:223-34.

in real life motivation. $\mathcal{F}$ Genet Psychol $1971 ; 118: 223-34$.
Kirton M. Characteristics of high Lie scorers. Psychol Rep 1977;40:279-80.

14 Bianchi GN, Fergusson DM. The effect of mental state on EPI scores. Br f Psychiatry 1977;131:306-9.

15 Lewey FH. Neurologic, medical and biochemical signs and symptoms indicating chronic industrial carbon disulfide absorption. Ann Intern Med 1941;15:869-83.

16 Grandjean E, Muchinger Rturrian V, Hass PA, et al. Investigations into the effects of exposure to trichloroethylene in mechanical engineering. Br f Ind Med 1955;12:131-42.

17 Lindstrom K, Martelin T. Personality and long term Lindstrom K, Martelin T. Personality and long term
exposure to organic solvents. Neurobehav Toxicol 1980;2: exposure

18 McSweeny AJ, Gant I, Heaton RK, et al. Relationship of neuropsychological status to every day functioning in healthy and chronically ill persons. $\mathcal{F}$ Clin Exp Neuropsychol 1985;7:281-91.

9 Lezak MD. Living with the characterologically altered brain injured patient. F Clin Psychiatry 1978;39:592-8.

20 Thomsen IV. The patient with severe head injury and his family: a follow up study of 50 patients. Scand $\mathcal{F}$ Rehabil Med 1974;6:180-3.

21 Lezak MD. Brain damage is a family affair. $\mathcal{F}$ Clin Exp Neuropsychol 1988;10:111-23.

22 Arlien-Söborg P. Solvent neurotoxicity. Boca Raton, Fl: CRC Press, 1992. 